\title{
'Knowledge of breast feeding and timely initiation of it amongst post natal mothers : An experience from a baby friendly teaching hospital of a metropolitan city'
}

\author{
Dr. Sarmila Mallik ${ }^{1}$,Dr. Urmila Dasgupta ${ }^{2}$,Dr. Subhrajyoti Naskar ${ }^{3}$,Dr. \\ Debjani Sengupta $^{4}$,Dr. Kantibhusan Choudhury ${ }^{5}$,Dr. Salil Kumar \\ Bhattacharya $^{6}$ \\ ${ }^{1,5,6}$ Faculty member of Community Medicine, Calcutta National Medical College, Kolkata, India \\ ${ }^{2,4}$ Faculty members of Community Medicine, Medical College, Kolkata,India. \\ ${ }^{3}$ Faculty member of Community Medicine, Malda Medical College, Malda, India
}

\begin{abstract}
Background:_The benefits of breastfeeding for the health and wellbeing of the mother and baby are well documented. WHO recommends early (i.e. within one hour of giving birth) initiation of breastfeeding. Objectives: To assess the knowledge of breast-feeding and the practices regarding initiation of breast feeding among postnatal mothers as well as to find their association with various factors if any.Settings: Postnatal ward of Calcutta National Medical College \& Hospital, Kolkata.Study design: Hospital based descriptive study.Participants: Postnatal mothers.Methodology:_Systematic random sampling was done for interview of 620 mothers. Various data were recorded and analyzed._Results: Around 51\% mothers were in the age group of 20-25, 15\% were illiterate and about 75\%were of the socio=economic class III and IV and $70 \%$ came from joint family. About $88 \%$ mothers had good knowledge score which was used here as the yardstick of knowledge measurement. Variables like increasing age, education, better socioeconomic status, joint family affected knowledge favorably, whereas age of mother below 20, first childbirth adversely affected the score. Also knowledge regarding initiation of breast feeding and duration of continuation of it was poor. Knowledge score did not influence the practice of timely initiation of breastfeeding, but the prelacteal feeding was favorably affected by it.
\end{abstract}

Key words: breastfeeding knowledge, hospital practices, initiation of breastfeeding, socio- demography

\section{Introduction:}

The benefits of breastfeeding for the health and wellbeing of the mother and baby are well documented. WHO recommends early (i.e. within one hour of giving birth) initiation of breastfeeding. A recent trial has shown that early initiation of breastfeeding could reduce neonatal mortality by $22 \%{ }^{1}$ which would contribute to the achievement of the Millennium Development Goals. In many parts of the world, the rates of early initiation of breastfeeding are extremely low: 17\% in Eastern Europe and Central Asian countries, and 33\% in AsiaPacific ${ }^{2}$ The highest rates (about 50\%) are in Latin America, the Caribbean, East and North Africa. However, for many countries no data are available.

Adequate nutrition during infancy is essential to ensure the growth, health, and development of children to their full potential ${ }^{3}$.

Breastfeeding confers short-term and long-term benefits on both child and mother including helping to protect children against a variety of acute and chronic disorders ${ }^{4}$.According to a study conducted in rural Ghana, it was concluded that if all women initiated breastfeeding within 1 hour of birth, $22 \%$ of the infants would be saved from death. In the Indian context, this means that 250,000 neonates can be saved from death annually by just one act - initiation of breastfeeding within 1 hour of birth ${ }^{5}$.

The key to successful breastfeeding is Information, Education and Communication (IEC) strategies aimed at behavior change. Very few women in India have access to counseling services on infant and young child feeding ${ }^{6}$. With these views the present study was carried out to assess the knowledge of breast-feeding and the practices regarding initiation of breast feeding among postnatal mothers as well as to find their association with various factors (socio demographic and socio economic); if any.

\section{Methodology:}

This descriptive type of observational, cross sectional study was carried out in the postnatal ward of Calcutta National Medical College, a tertiary care baby friendly hospital of West Bengal from November2010 to February 2011. Breastfeeding was initiated within one hour in $43 \%$ of the infants, between one hour and the end of the first day of birth in $28 \%$ of the infants, and by the end of day 3 in all but $1.3 \%$ of them ${ }^{7}$. So applying the 
formula $4 \mathrm{pq} / \mathrm{l}^{2}$ and considering $\mathrm{p}=40$ (allowable error $10 \%$ ), the sample size calculated was 600 . Average delivery per month was $600.30 \%$ of 4 months' deliveries and excluding mothers who were sick, had lost their babies, whose babies were sick or very low birth weight or who were not willing to participate , total 620 mothers were interviewed using a predesigned, pretested schedule after obtaining informed verbal consent from them. Every 3rd postnatal mother delivered during study period was included for the study. Everyday data were collected by trained female internees and female faculties. Duplication was carefully avoided. Schedule was consisted of socio demographic correlates of respondents, their knowledge on breast feeding and initiation of breastfeeding and hospital practice regarding breastfeeding. Knowledge part contains 17 questions; A scoring mechanism was used to understand over all knowledge level; a score of one has given for each correct response and zero for wrong response. Respondents with all correct response got a maximum of 17 points, higher points indicate good knowledge. Based on total score, knowledge level on breast feeding was categorized into poor ( $<13$ points), good ( $\geq 13$ points).Socio economic class of respondents was determined according to modified B.G.Prasad Scale(again modified by A.K.Agarwal). The variables used in this study were age, type of family, education, socio - economic status, residence, parity of mother, their knowledge score, and practices regarding initiation of breast feeding.

Data entry was done in MS-EXCEL and was analyzed by SPSS 16.

\section{Results:}

Concerning socio-demographic profile,(TableI),out of 620 mothers ,majority(51.9\%) were in the age group of 20-25 years and $24.1 \%$ were teen -age mothers. $70 \%$ of them came from joint family. Majority of mothers had primary(35.9\%) and secondary education(37.9\%), while $15.9 \%$ were illiterate and $10.3 \%$ had education H.S and above. Regarding socio-economic status, a large portion mothers belonged to class III (38.4\%) and class IV(36.6\%). 60.0\% mothers were primipara, rest had parity 2 or more. $61.9 \%$ had vaginal delivery and rest had C.S. $57.9 \%$ mother came from rural area, while $42.1 \%$ from urban area.

Regarding knowledge of breast feeding,(Table II), percentage of mothers having correct knowledge was more than $75 \%$ for most of the items, except for time of initiation of breastfeeding in cesarean section and duration of continuation of breast feeding where correct knowledge was present in $65.2 \%$ and $41.9 \%$ respectively. In $88.1 \%$ mothers knowledge score was good i.e. 13 or more whereas $11.9 \%$ mothers had poor knowledge score i.e. less than 13(Table III).

Table IV showed that percentage of women with good knowledge score( 13 and above) increased with the increase of age, educational status, parity and improvement of socio-economic status .Knowledge score was good in $80.5 \%$ mothers below 20 years, $89.8 \%$ between $20-25$ years, $91.2 \%$ between $26-30$ years and $100 \%$ in mothers above 30 years. The difference was significant between the age groups of below 20 years and 20-25 years, but not significant between other age groups. $74.7 \%$ illiterate mothers and $86.9 \%$ primary educated mothers had good knowledge score, whereas good knowledge score was found in $93.2 \%$ mothers having secondary education, $92.0 \%$ with higher secondary education and $100 \%$ with education graduate and above. The difference was significant between illiterate and primary educated and also between primary and secondary educated, but not significant among secondary, higher secondary and graduate and above groups. More than $90 \%$ mothers belonging to SE status I,II,III had good knowledge score, but only $85.5 \%$ mothers belonging to SE status IV, and $75.8 \%$ of status V and VI had good knowledge score. The difference was significant between SE status I,II,III and SE status IV, as well as between SE status IV and SE status V and VI. Knowledge score was good in $82.3 \%$ of primipara and in $96.4 \%$ mothers with parity 2 and $100 \%$ with parity 3 or more. The difference was statistically significant. $88.6 \%$ rural and $87.4 \%$ urban mothers had good knowledge score. The difference was not significant. Knowledge score 13 and above was found in $77.9 \%$ mothers from nuclear family and $92.4 \%$ mothers from joint family. The difference was significant. Regarding hospital practices(Table V), most of the babies(99.2\%) kept in the same room with the mother.87.9\% mothers were told about benefits and management of breast feeding, and $84.0 \%$ were shown the techniques of breast feeding. Baby was put to breast immediately after handover in $66.1 \%$ cases and prelacteal feeding was done in only $15.0 \%$ cases.

According to Table VI, almost equal proportion of mothers(66.1\% and $66.2 \%)$ with good and poor knowledge score put their babies to breast immediately, but $27.0 \%$ mothers with poor knowledge score and $13.3 \%$ with good score practiced prelacteal feeding. This difference was statistically significant.

\section{Discussion:}

In this study the knowledge of postnatal mothers regarding breast feeding was quite good, more than $85 \%$ mothers having correct knowledge for most of the items and $88.1 \%$ mothers had good knowledge score. The study of Kishore Sunil et. al found 39\% of mothers had satisfactory breast feeding knowledge. ${ }^{8}$

In the present study it was observed that correct knowledge about the time of initiation of breast feeding in vaginal delivery and caesarean section was present in $76.9 \%$ and $65.2 \%$ of mothers respectively. More than 90\% mothers had correct knowledge regarding number of feeding in 24 hours, breast feeding at 
night, on demand breast feeding, duration of each episode of breast feeding, breast feeding better than bottle feeding, importance of colostrum feeding. Correct knowledge regarding prelacteal feeding in vaginal delivery and in C.S was present in $85.9 \%$ and $84.8 \%$ of postnatal mothers respectively.87.1\% mothers knew correctly the duration of exclusive breastfeeding, but $41.9 \%$ mother had correct knowledge regarding duration of continuing breastfeeding. The study of Chaudhury RN et al found that mothers did not have adequate knowledge about the appropriate way of breastfeeding. They observed that only $10 \%$ mothers had correct knowledge regarding time of initiation of breastfeeding and prelacteal feeding, 25\% had an idea on importance of colostrum, $15 \%$ knew the meaning of exclusive breastfeeding and $15 \%$ mothers had an idea of importance of night feeding. ${ }^{9}$ In this study the knowledge score improved with increase in age, educational status, parity, in mothers from joint family, and with improvement of socio-economic status, but almost same in both rural and urban mothers. In a Nigerian study, significantly higher proportion of mothers with at least secondary education initiated breast feeding in 1 hour, avoided prelacteal feeding and practiced exclusive breastfeeding for 6months, maternal education below secondary level strongly contributed to prelacteal feeding and failure of exclusive breastfeeding. ${ }^{10}$. Regarding hospital practices most of the babies $(99.2 \%)$ were kept in the same room with the mother.87.9\% mothers were told about benefits and management of breast feeding, and $84.0 \%$ were shown the techniques of breast feeding. Baby was put to breast immediately after handover in $66.1 \%$ cases and prelacteal feeding was done in only15.0\% cases. In Vardhan Medical College and Safdarjang Medical College, New Delhi,2001-2002, it was found that only $15 \%$ of mothers initiated breast feeding within 2 hours ${ }^{11}$ In USA 2009 most hospitals $(92.8 \%)$ provided prenatal breastfeeding education and $89.1 \%$ showed breast feeding technique.$^{12}$ In California 2010,89\% of mothers were rooming-in, $66 \%$ of mothers had early initiation of breastfeeding. ${ }^{13}$ In the Nepal study none of the mothers got breastfeeding advice in antenatal care, $41.5 \%$ of mothers initiated breastfeeding within $1 / 2$ hour. ${ }^{9}$ In Vadodara city, 2010 it was found $32.6 \%$ of mothers initiated breastfeeding within 1hour of delivery in a tertiary care hospital ${ }^{14}$ Gover et. al in their study in East Delhi found that only $9.1 \%$ infants were breastfed within one hour and $71.7 \%$ mothers agreed that breastfeeding protects from infection and is the healthiest food. ${ }^{15}$ In the present study time of initiation of breast feeding was not influenced by knowledge score, as almost equal proportion of mothers $(66.1 \%$ and $66.2 \%)$ with good and poor knowledge score put their babies to breast immediately, which may be due to inconvenient hospital environment. But practice of prelacteal feeding was significantly higher in good knowledge group.

\section{Conclusion:}

The qualitative aspect of knowledge regarding infant feeding have been quantified in this study in form of a score enabling distinct identification of factors affecting it. The findings showed variables like increasing age, education, better socioeconomic status, joint family affected knowledge favorably, whereas age of mother below 20, first childbirth adversely affected the score . However knowledge score regarding two aspects of prime importance namely timely initiation(following caesarean section) and duration of breast feeding was rather low (65\% and $41.9 \%$ respectively) defying all favorable knowledge for other aspects, so that the practice of immediate initiation of breast feeding was only around $66 \%$ even in good knowledge score group. Among mothers having a good score suggesting good knowledge prelacteal feeding was low as compared to the poor knowledge group. So counseling, and demonstration of breast feeding could improve the initiation practice.As noted earlier neonate and infant feeding practices if properly implemented can go a long way in ensuring a positive health of the future generation.

\section{References:}

[1] Edmond KM, Zandoh C, Quigley MA, Amenga-Etego S, Owusu-Agyei S, Kirkwood BR. Delayed breastfeeding initiation increases risk of neonatal mortality. Pediatrics 2006;117:380-386

[2] Better breastfeeding, healthier lives. Population Reports Series L No.14, Baltimore; MD, USA .Available at http://www.infoforhealth.org/pr/114/webtables.shtml\#webtable and http://www.infoforhealth.org/pr/114/webtables.shtml\#webtable 2); accessed 24 Jan 2009

[3] World Health Organization. The global burden of disease: 2004 update. Geneva, World Health Organization, 2008

[4] Leon-Cava N, Lutter S, Ross J, Martin L. Quantifying the benefits of breastfeeding: A summary of the evidence. Pan American Health Organization, Washington DC, 2002

[5] Gupta A, Arora V, Bhatt B. The State of World's Breastfeeding: India Report card 2006. International Baby Food Action Network (IBFAN), Asia Pacific. India. 2006

[6] Dadhich JP, Gupta A. Assessment of Status of Infant and Young Child Feeding (IYCF) practice, policy and program-Achievements and Gaps. Breast feeding pro-motion network of India. 2005

[7] (http://fex.ennonline.net/28/neonatal.aspx )

[8] Kishore M. Sal Sunil, Kumar Praveen and Aggarwal Arun K. Breastfeeding Knowledge and Practices amongst Mothers in a Rural Population of North India: A Community- based study. Journal of Tropical Pediatrics. Vol 55 Issue3 :183-188

[9] Chaudhury RN, Shah T, Raja S. Knowledge and practice of mothers regarding breastfeeding: a hospital based study. Health Renaissance.Vol9,No3(2011).

[10] Oqunlin TA. Maternal socio-demographic factors influencing initiation and exclusivity of breastfeeding in a Nigerian semi-urban setting. Child Health J 2010 May, 14(3) 459-65.

[11] Saxena.P.Contemporary breastfeeding practices-A hospital based study, Indian J.Prev.Soc.Medicine ;Vol. 37 No.3\&4,2006. 
[12] Centre for disease control and prevention, MMWR ,August 2011; early release/vol.60

[13] Hospital practices and breastfeeding ,Maternal and Infant health assessment survey,2010; Maternal, child, adolescent health, California department of public health.

[14] Bhatt $\mathrm{S}$ et al. Knowledge, attitude and practice of postnatal mothers for early initiation of breastfeeding in the obstetric wards of a tertiary care hospital of Vadodara city, National Journal of Community Medicine; Vol 3 Issue 2, April-June 2012.

[15] Gover Vijay L, Chhabra Pragti, and Aggarwal O.P. Breastfeeding in a rural area of East Delhi. Health and Population-Perspectives and Issues. 20(2): 49-56,1997.

TABLE I:Distribution of postnatal mothers according to their socio demographic profile, parity and type

\begin{tabular}{|l|l|l|}
\hline Socio demographic profile & \multicolumn{1}{|c|}{ No. of mothers } & Percentage \\
\hline Age in years & & \\
\hline Below 20 & 149 & 24.1 \\
\hline $20-25$ & 322 & 51.9 \\
\hline $26-30$ & 136 & 21.9 \\
\hline Above 30 & 13 & 2.1 \\
\hline Type of family & & \\
\hline Nuclear & 186 & 30.0 \\
\hline Joint & 434 & 70.0 \\
\hline Education & & \\
\hline Illiterate & 99 & 15.9 \\
\hline Primary & 223 & 35.9 \\
\hline Secondary & 235 & 37.9 \\
\hline Higher secondary & 50 & 8.2 \\
\hline Graduate \& above & 13 & 2.1 \\
\hline S-E Status & & \\
\hline I & 14 & 2.3 \\
\hline II & 46 & 7.4 \\
\hline III & 238 & 38.4 \\
\hline IV & 227 & 36.6 \\
\hline V\&VI & 95 & 15.3 \\
\hline Parity & & \\
\hline 1 & 372 & 60.0 \\
\hline 2 & 223 & 35.9 \\
\hline 3 \& more & 25 & 4.1 \\
\hline Type of delivery & & \\
\hline Normal & 384 & 61.9 \\
\hline C.S & 236 & 38.1 \\
\hline Residence & & 57.9 \\
\hline Rural & 359 & 42.1 \\
\hline Urban & 261 & \\
\hline & & \\
\hline
\end{tabular}

TABLE II:Distribution of postnatal mothers according to their knowledge regarding breast feeding $(\mathbf{N}=620)$

\begin{tabular}{|l|l|l|}
\hline \multirow{2}{*}{ Items } & Correct & \multicolumn{2}{l|}{ Knowledge } \\
\cline { 2 - 3 } & Number & Percentage \\
\hline Time of initiation of breast feeding in vaginal delivery & 477 & 76.9 \\
\hline Time of initiation of breast feeding in caesarean section & 404 & 65.2 \\
\hline Prelacteal feeding in vaginal delivery & 533 & 85.9 \\
\hline Prelacteal feeding in caesarean section & 526 & 84.8 \\
\hline No. of feeding in 24 hours & 616 & 99.4 \\
\hline Breast feeding done at night & 607 & 97.9 \\
\hline Time interval between breastfeeds & 577 & 93.1 \\
\hline Duration of each episode of breast feeding & 583 & 94.0 \\
\hline Breast milk better than Commercial baby food & 502 & 80.9 \\
\hline Breast milk given to baby when baby is ill & 515 & 83.1 \\
\hline Breast milk given to baby when mother is ill & 521 & 84.0 \\
\hline
\end{tabular}




\begin{tabular}{|l|l|l|}
\hline Breast feeding is better than bottle feeding & 595 & 95.9 \\
\hline First yellow milk to be given to the baby & 577 & 93.1 \\
\hline Yellow milk is beneficial to the baby & 564 & 90.9 \\
\hline Duration of exclusive breast feeding & 540 & 87.1 \\
\hline Duration of continuing breast feeding & 260 & 41.9 \\
\hline Ways to know whether breast feeding adequate & 552 & 89.0 \\
\hline
\end{tabular}

TABLE III:Distribution of postnatal mothers according to their knowledge score regarding breast feeding

\begin{tabular}{|l|l|l|}
\hline Knowledge Score & Number & Percentage \\
\hline$<13$ & 74 & 11.9 \\
\hline$>=13$ & 546 & 88.1 \\
\hline Total & 620 & 100 \\
\hline
\end{tabular}

TABLE IV:Association of knowledge score regarding breast feeding with different factors

\begin{tabular}{|c|c|c|c|c|c|c|}
\hline \multirow{3}{*}{$\begin{array}{l}\text { Factors } \\
\text { Age in years }\end{array}$} & \multirow[t]{3}{*}{ Total } & \multicolumn{4}{|c|}{ Knowledge Score } & \multirow[t]{3}{*}{$\mathrm{p}$ value } \\
\hline & & \multicolumn{2}{|l|}{$<13$} & \multicolumn{2}{|c|}{$>=13$} & \\
\hline & & No. & $\%$ & No. & $\%$ & \\
\hline & 149 & 29 & 19.5 & 120 & 80.5 & \multirow{2}{*}{$\begin{array}{l}X^{2}=7.56 \mathrm{df}=1 \\
\mathrm{p}<0.05\end{array}$} \\
\hline $20-25$ & 322 & 33 & 10.2 & 289 & 89.8 & \\
\hline $26-30$ & 136 & 12 & 8.8 & 124 & 91.2 & $\begin{array}{l}X^{2}=0.22 \\
d f=1, p>0.05\end{array}$ \\
\hline Above 30 & 13 & 0 & 0 & 13 & 100 & $\begin{array}{l}X^{2}=0.34 \\
d f=1, p>0.05\end{array}$ \\
\hline \multicolumn{7}{|l|}{ Type of family } \\
\hline Nuclear & 186 & 41 & 22.1 & 145 & 77.9 & \multirow{2}{*}{$\begin{array}{l}\mathrm{X}^{2}=25.82 \\
\mathrm{df}=1, \mathrm{p}<0.05\end{array}$} \\
\hline Joint & 434 & 33 & 7.6 & 401 & 92.4 & \\
\hline \multicolumn{7}{|l|}{ Education } \\
\hline Illiterate & 99 & 25 & 25.2 & 74 & 74.7 & \multirow{3}{*}{$\begin{array}{l}X^{2}=7.36 \\
d f=1, p<0.05 \\
X^{2}=4.95 \quad d f=1, \\
p<0.05\end{array}$} \\
\hline Primary & 223 & 29 & 13.0 & 194 & 86.9 & \\
\hline Secondary & 235 & 16 & 6.8 & 219 & 93.2 & \\
\hline Higher secondary & 50 & 4 & 8.0 & 46 & 92.0 & \multirow{2}{*}{$\begin{array}{l}X^{2}=1.07 \\
d f=2, p>0.05\end{array}$} \\
\hline Graduate \& above & 13 & 0 & 0 & 13 & 100 & \\
\hline \multicolumn{7}{|l|}{ S-E Status } \\
\hline I & 14 & 1 & 7.2 & 13 & 92.8 & \multirow{5}{*}{ 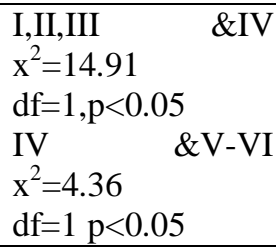 } \\
\hline II & 46 & 3 & 6.5 & 43 & 93.5 & \\
\hline III & 238 & 14 & 5.9 & 224 & 94.1 & \\
\hline IV & 227 & 33 & 14.5 & 194 & 85.5 & \\
\hline $\mathrm{V} \& \mathrm{VI}$ & 95 & 23 & 24.2 & 72 & 75.8 & \\
\hline \multicolumn{7}{|l|}{ Parity } \\
\hline 1 & 372 & 66 & 17.7 & 306 & 82.3 & \multirow{3}{*}{$\begin{array}{l}X^{2}=30.10 \quad d f=2, \\
p<0.05\end{array}$} \\
\hline 2 & 223 & 8 & 3.6 & 215 & 96.4 & \\
\hline 3 \&more & 25 & 0 & 0 & 25 & 100 & \\
\hline \multicolumn{7}{|l|}{ Residence } \\
\hline Rural & 359 & 41 & 11.4 & 318 & 88.6 & \multirow{2}{*}{$\begin{array}{l}X^{2}=0.24 \\
d f=1, p>0.05\end{array}$} \\
\hline Urban & 261 & 33 & 12.6 & 228 & 87.4 & \\
\hline
\end{tabular}


TABLE V: Hospital Practices regarding breast feeding ( $N=620)$

\begin{tabular}{|l|l|l|l|l|}
\hline \multirow{2}{*}{ Items } & \multicolumn{2}{l|}{ No } & \multicolumn{1}{l|}{} \\
\cline { 2 - 5 } & Number & $\%$ & Number & $\%$ \\
\hline $\begin{array}{l}\text { Mother was told about the benefits and managements of } \\
\text { breastfeeding in hospital }\end{array}$ & & & & \\
\hline Mother was shown the technique of breastfeeding & 545 & $87.9 \%$ & 75 & $12.1 \%$ \\
\hline Baby was kept in same room as the mother & 521 & $84.0 \%$ & 99 & $16.0 \%$ \\
\hline $\begin{array}{l}\text { Baby was given breast immediately after being hand over to } \\
\text { mother }\end{array}$ & 615 & $99.2 \%$ & 5 & $0.8 \%$ \\
\hline Prelacteal food was given to the baby & 410 & $66.1 \%$ & 210 & $33.9 \%$ \\
\hline
\end{tabular}

TABLE VI:Association of knowledge score with practices regarding initiation of breast feeding $(\mathrm{N}=620)$

\begin{tabular}{|c|c|c|c|c|c|c|c|c|c|c|c|}
\hline \multirow{4}{*}{$\begin{array}{l}\text { Knowledge } \\
\text { Score }\end{array}$} & \multirow[t]{4}{*}{ Total } & \multicolumn{9}{|c|}{ Breast feeding practices } & \multirow{5}{*}{$\begin{array}{l}\mathrm{p} \text { value } \\
\mathrm{X}^{2}=9.53 \\
d \mathrm{f}=1 \\
\mathrm{p}<0.05\end{array}$} \\
\hline & & \multicolumn{4}{|c|}{ Baby put to breast immediately } & \multirow{3}{*}{$\begin{array}{l}p \\
\text { value } \\
d f=1 \\
p>0.05\end{array}$} & \multicolumn{4}{|c|}{ Prelacteal Feeding } & \\
\hline & & \multicolumn{2}{|l|}{ Yes } & \multicolumn{2}{|l|}{ No } & & \multicolumn{2}{|l|}{ Yes } & \multicolumn{2}{|l|}{ No } & \\
\hline & & No. & $\%$ & No. & $\%$ & & No. & $\%$ & No. & $\%$ & \\
\hline$<13$ & 74 & 49 & 66.2 & 25 & 33.2 & & 20 & 27.0 & 54 & 73.0 & \\
\hline$>=13$ & 546 & 361 & 66.1 & 185 & 33.9 & & 73 & 13.3 & 473 & 86.7 & \\
\hline Total & 620 & 410 & 66.1 & 210 & 33.9 & & 93 & 15.0 & 527 & 85.0 & \\
\hline
\end{tabular}

